\title{
中国先进半导体材料及辅助材料发展战略研究
}

\author{
“先进半导体材料及辅助材料”编写组
}

\begin{abstract}
摘要: 目前, 以 $\mathrm{SiC} 、 \mathrm{GaN}$ 为代表的第三代半导体材料快速发展, 我国亟需抓住战略机遇期, 实现先进半导体材料、辅助材 料的自主可控, 保障相关工业体系安全。本文在分析全球半导体材料及辅助材料研发与产业发展现状的基础上, 寻找差距, 结合我国现实情况，提出了构建半导体材料及辅助材料体系化发展、上下游协同发展和可持续发展的发展思路，制定了面向 2025 年和 2035 年的发展目标。为推动我国先进半导体材料及辅助材料产业发展, 提出了建设集成电路关键材料及装备自主 可控工程, $\mathrm{SiC}$ 和 $\mathrm{GaN}$ 半导体材料、辅助材料、工艺及装备验证平台, 先进半导体材料在第五代移动通信技术、能源互联网 及新能源汽车领域的应用示范工程, 并对如何开展三项工程进行了需求分析, 设置了具体的工程目标和工程任务。最后, 为 推动半导体产业的创新发展，从坚持政策推动，企业和机构主导，整合国内优势资源; 把握 “超越摩尔” 的历史机遇，布局 下一代集成电路技术; 构建创新链, 进行创新生态建设等方面提出了对策建议。
\end{abstract}

关键词：先进半导体材料；辅助材料；第三代半导体； 2035

中图分类号: TN304 文献标识码：A

\section{Strategic Study on the Development of Advanced Semiconductor Materials and Auxiliary Materials in China}

\author{
Writing Group of Advanced Semiconductor Materials and Auxiliary Materials
}

\begin{abstract}
The rapid development of the third-generation semiconductor materials represented by SiC and GaN offers China a strategic opportunity to realize the independent control over its advanced semiconductor materials and auxiliary materials sector and to ensure the security of relevant industrial systems. In this paper, we analyze the development status of semiconductor materials and auxiliary materials in China and abroad, propose the idea of systematic, upstream-downstream coordinated, and sustainable development, and set the development goals for these materials by 2025 and 2035. To promote the development of advanced semiconductor materials and auxiliary materials in China, we suggest the establishment of a project for realizing independent control over key material and equipment of integrated circuit; a platform that provides integrated tests for $\mathrm{SiC}$ and $\mathrm{GaN}$ semiconductor materials, auxiliary materials, processes, and equipment; and application demonstration projects for advanced semiconductor materials in the fifth-generation mobile communication, energy internet, and new energy vehicle fields. Demand analysis regarding these projects is conducted and specific project objectives and tasks are proposed correspondingly. To promote the innovative development of the semiconductor industry, China should adhere to government guidance to facilitate the integration of domestic advantageous resources, grasp the "More Than Moore" opportunity of to lay out the next-generation integrated circuit technologies, and construct an innovation chain to further improve the innovation ecology.
\end{abstract}

Keywords: advanced semiconductor materials; auxiliary materials; third-generation semiconductor; 2035

收稿日期 : 2020-07-15; 修回日期 : 2020-08-31

联系人：于坤山, 第三代半导体产业技术创新战略联盟秘书长; E-mail: kshanyu@126.com

资助项目：中国工程院咨询项目 “新材料强国 2035 战略研究” (2018-ZD-03)

本刊网址：www.engineering.org.cn/ch/journal/sscae 


\section{一、前言}

经过 60 多年的发展, 全球半导体材料出现了 三次突破性的发展进程。第一代半导体材料 $\mathrm{Si}$ 和 $\mathrm{Ge}$ 奠定了计算机、网络和自动化技术发展的基础, 第二代半导体材料砷化镓 (GaAs) 和磷化铟 (InP) 奠定了信息技术的发展基础, 而目前正在快速发展 的第三代半导体材料碳化硅 $(\mathrm{SiC})$ 、氮化镓 $(\mathrm{GaN})$ 、 氧化镓 $\left(\mathrm{Ga}_{2} \mathrm{O}_{3}\right)$ 、氮化铝 $(\mathrm{AlN})$ 、金刚石 $(\mathrm{C})$ 等, 主要面向新一代电力电子、微波射频和光电子应用, 在新一代移动通信、新能源并网、智能电网、高速 轨道交通、新能源汽车、消费类电子、新一代显示 等领域有广阔的应用前景, 成为全球半导体产业发 展新的战略高地 [1]。

我国的半导体材料和器件, 长期依赖进 口 $[2,3]$, 其中高性能芯片完全依赖进口, 受制于 人的问题突出。除芯片设计与制造能力薄弱外, 半导体单晶硅和大量辅助材料的国产化水平不足, 进口依赖程度较高, 如在电子气体、光刻胶和抛 光材料等 3 种典型辅助材料领域, 国内企业生产 的产品市场占有率分别仅占 $30 \% 、 10 \% 、 10 \%$, 亟需提升我国半导体关键原辅材料的自主保障能 力。中美贸易摩擦的升级和 2020 年新型冠状病 毒肺炎疫情的出现, 将对全球先进半导体材料和 辅助材料供应链安全与产业链分工产生持续影响。 目前，美国及其伙伴国将一些关键材料、生产装 备列入管制清单，危及我国半导体产业和相关工 业体系的安全。因此, 实现先进半导体材料、辅 助材料、关键技术、重要装备等的自主可控刻不 容缓。

当然, 随着以 $\mathrm{SiC} 、 \mathrm{GaN}$ 为代表的第三代半导 体技术和产业发展, 未来高质量 $\mathrm{SiC}$ 单晶祄底及其 同质 / 异质外延材料、大尺寸 $\mathrm{Si}$ 上 $\mathrm{GaN}$ 外延材料 将在光电子、电力电子和微波/射频领域发挥重要 作用 $[4,5]$ 。在新一代半导体材料领域, 我国已经具 备良好的产业化基础 [6 8]。新的半导体材料体系 的出现, 是一次与发达国家同台竞争的极佳机会, 及时把握这一历史机遇，通过整合优质资源、突破 核心技术、打造本土产业链, 以期实现新一代半导 体产业的自主可控。

\section{二、全球半导体材料及辅助材料的研发与产 业发展现状}

\section{（一）国外研发与产业发展现状}

在半导体 $\mathrm{Si}$ 晶圆领域 [9], 全球约有 $94 \%$ 的 市场份额由少数企业占据, 如信越化学工业株式 会社、胜高科技株式会社、环球晶圆股份有限公 司、德国世创 (Siltronic) 公司和韩国海力士（SK Siltron）公司。在半绝缘 GaAs 单晶及其外延材料 领域, 全球约有 $95 \%$ 的市场份额来自住友电气工 业株式会社、弗莱贝格化合物材料公司和美国晶体 技术（AXT）有限公司。

在 $\mathrm{GaN}$ 体单晶材料领域, 住友电气工业株式 会社、日立电线株式会社、古河机械金属株式会社 和三菱化学控股集团等的代表性企业可批量提供 2 3 in (1 in=2.54 cm) $\mathrm{GaN}$ 体单晶材料 [9], 约占 全球市场份额的 $85 \%$ 以上，同时，这几家企业还可 提供小批量 4 in $\mathrm{GaN}$ 体单晶材料。尽管我国已成为 白光 LED 芯片及半导体照明灯具的生产大国，但 在 LED 外延材料生产及其芯片制备技术方面较为 薄弱， $70 \%$ 以上的核心专利技术由美国、日本、德 国等国家掌握, 如汽车前灯等高端应用所需的功率 型白光 LED 芯片主要是由美国流明 (Lumileds) 公 司提供。

目前, $\mathrm{SiC}$ 单晶祄底领域形成了美国、欧洲、 日本三方垄断的局面 [9]。其中, 全球最大的 $\mathrm{SiC}$ 单 晶供应商是美国科锐公司, 占 $85 \%$ 以上的全球市 场份额。

在集成电路辅助材料方面 [9], 光刻胶的市场 集中度非常高, 少数企业基本垄断了全球光刻胶市 场, 代表性的企业有日本合成橡胶株式会社（JSR）、 东京应化工业株式会社、住友化学株式会社、信越 化学工业株式会社、罗门哈斯公司等。在掩膜版 方面, 美国福尼克斯（Photronics）公司、日本印 刷（DNP）株式会社、日本凸版印刷（Toppan）株 式会社三家公司占据了全球 $80 \%$ 以上的市场份额。 在集成电路用抛光液方面, 市场主要由美国卡博特 （Cabot Microelectronics）公司、荷兰阿克苏诺贝尔 公司、德国拜耳公司、日本富士美株式会社等企业 垄断，占据了全球 $90 \%$ 以上的市场份额。 


\section{（二）国内研发及产业发展现状}

到目前为止, 在晶圆制造方面, 我国新增 8 in 硅片设计产能将超过 $3.5 \times 10^{6}$ 片/月, 新增 $12 \mathrm{in}$ 硅 片设计产能将接近 $5 \times 10^{6}$ 片/月，芯片制造能力达 到全球的 $30 \%$ 左右。

依托宽禁带半导体 $\mathrm{GaN}$ 和 $\mathrm{SiC}$ 材料的发 展, 我国在祄底单晶生长、外延材料等方面已具 有了较强的技术研发和产业化竞争力, 蓝宝石基 $\mathrm{GaN}$ 外延材料已形成具有 7000 亿市场规模的半导 体照明产业, $\mathrm{Si}$ 基 $\mathrm{GaN}$ 外延材料开始在快充产品 中应用; 4 in $\mathrm{SiC}$ 高纯半绝缘和导电祄底及其异质 $(\mathrm{GaN})$ 外延和同质 ( $\mathrm{SiC})$ 外延材料已实现量产, 分别在微波射频和电力电子领域得到广泛应用。在 光纤通信技术的推动下, 我国在 $\mathrm{GaAs}$ 单晶及外延 材料技术方面取得突破, 为近红外激光器以及光纤 通信产业的发展提供了有力支撑。

在光刻胶方面, 我国的代表性生产企业有北京 科华微电子材料有限公司、苏州瑞红电子化学品有 限公司和潍坊星泰克微电子材料有限公司, 生产的 产品已经批量用于集成电路制造领域。目前已经实 现量产的是 $\mathrm{G} / \mathrm{I}$ 线光刻胶, 正逐步通过芯片企业认 证并开始小批量生产 $\mathrm{KrF}$ 光刻胶, 2020 年 $\mathrm{ArF}$ 光 刻胶能取得突破并完成认证。但是, 国内尚未具备 极紫外光刻 (EUV) 和电子束光刻胶的研发与生产 能力, 亟需突破。

在超净高纯试剂方面, 上海新阳半导体材料股 份有限公司生产的超纯电镀硫酸铜电镀液已进入 中芯国际集成电路制造有限公司的量产工艺制程, 浙江凯圣氟化学有限公司生产的高纯氢氟酸已通 过多条 8 in 和 12 in 生产线的认证并供货, 苏州晶 瑞化学股份有限公司开发的钛铇蚀刻液已实现进 口替代。

经过多年努力, 国产电子气体也取得明显突 破, $\mathrm{WF}_{6} 、 \mathrm{C}_{2} \mathrm{~F}_{6} 、 \mathrm{AsH}_{3} 、 \mathrm{PH}_{3}$ 等气体品种已大批量 应用于国内 8 in 生产线, $\mathrm{Cl}_{2} 、 \mathrm{HCl} 、 \mathrm{HF} 、 \mathrm{~N}_{2} \mathrm{O}$ 等 一批产品正在 8 12 in 生产线进行应用验证, 部分品种的激光气体也开始供应国内晶圆制造 企业。

在化学机械抛光 (CMP) 材料方面, 国内企 业研发的铜/铜阻挡层抛光液已进入国内外多家集 成电路制造企业的最新技术节点制程; 三维（3D） 硅通孔 (TSV) 抛光液在全球处于领先地位, 铇
抛光液逐步开始供应全球各大晶圆制造企业; CMP 垫、修整盘也进入评价验证阶段。

我国靶材产业发展速度很快, 以宁波江丰电 子材料股份有限公司、有研亿金新材料有限公司 为代表, 实现了半导体行业用全系列高纯金属 材料、溅射靶材和蒸发膜材的产业化, 包括 Ta、 $\mathrm{Cu} 、 \mathrm{Ti} 、 \mathrm{Co} 、 \mathrm{Al} 、 \mathrm{Ni} 、 \mathrm{Au} 、 \mathrm{Ag} 、 \mathrm{Pt} 、 \mathrm{Ru}$ 及其合 金。其中, 超高纯金属 $\mathrm{Ta} 、 \mathrm{Cu}$ 等溅射靶材已成功 通过台湾积体电路制造股份有限公司的考核, 在 $14 \mathrm{~nm} / 16 \mathrm{~nm}$ 技术节点的生产线实现了批量应用, 在 $10 \mathrm{~nm} / 7 \mathrm{~nm}$ 技术节点进行评价试用。

总体而言, 近年来我国半导体产业基础化学品 产业取得了较大进展, 伴随着国内对集成电路和半 导体产业的高度关注, 在晶圆制造、宽禁带半导体 材料、光刻胶、超净高纯试剂、电子气体、CMP材 料、靶材等方面产业发展势头良好, 但与高速发展 的产业需求相比, 仍存在整体生产能力较弱、研 发能力不足等问题未得到根本改变, 亟需进一步 突破 [9]。

\section{三、我国先进半导体材料及辅助材料的发展 思路与目标}

\section{（一）发展思路}

为促进半导体产业的发展, 我国先进半导体材 料及辅助材料今后的发展思路为: 构建梯次发展的 半导体材料体系, 每一个材料体系做到单晶、外延、 芯片工艺、封装等上下游协同, 不断创新, 推动先 进半导体材料及其辅助材料的可持续发展。

第一, 成体系发展。自半导体材料诞生以来, 从 $\mathrm{Si} 、 \mathrm{Ge}$ 到 $\mathrm{GaAs} 、 \mathrm{InP}$, 再到 $\mathrm{SiC} 、 \mathrm{GaN}$, 可以看 出, 半导体相关技术和产业的发展都是围绕主要材 料制备、器件工艺需要和芯片来进行的, 并逐渐发 展为一个完整的材料体系。基于此, 在不断完善我 国 $\mathrm{Si}$ 基材料体系的同时, 要及时把握各种新型化合 物半导体材料的技术突破和产业化应用的机会, 构 建自主可控的新型半导体材料体系。

第二, 上下游协同发展。半导体产业链包含原 材料、单晶生长和外延、芯片设计与制备工艺、封 测与应用以及支撑各环节的核心装备与关键零部件 等环节, 产业链长且各环节工艺复杂, 任一环节出 现问题都将导致最终的器件性能不达标。因此, 要 
以提供满足应用需求的器件为目标, 通过上下游协 同发展实现全产业链的整体技术突破。

第三, 可持续发展。在实施追赶战略的同时, 我国先进半导体材料及辅助材料的发展还需要把握 未来技术发展趋势，在不断积累已有技术经验的同 时, 关注新的材料体系、芯片结构和工艺的发展变 化, 积极探索与创新, 确保可持续发展。

\section{（二）发展目标}

\subsection{5 年发展目标}

我国半导体材料及辅助材料 2025 年的发展目 标是：核心半导体材料技术达到国际先进水平，相 关产品满足产业链的安全供应需要, 建立起全产业 链能力, 解除关键行业的 “卡脖子” 问题。

\section{（1）集成电路用半导体材料}

加强 12 in $\mathrm{Si}$ 单晶及其外延材料的技术研究, 逐步扩大国产材料的市场应用份额。实现 8 in $\mathrm{Si}$ 材 料国内市场的完全自主供应, 确保 12 in 单晶 $\mathrm{Si}$ 及 其外延材料产能及市场占有率，同时发展更大尺寸 单晶 $\mathrm{Si}$ 及其外延材料的制造技术, 确保我国集成 电路产业的可持续发展。

\section{(2) 功率器件用半导体材料}

抓住 $\mathrm{Si}$ 基电力电子器件产业转移的契机, 做 大电力电子器件的产业规模, 加紧推进 $\mathrm{SiC} 、 \mathrm{GaN}$ 电力电子器件产业化。实现 6 in 无微管缺陷 $\mathrm{SiC}$ 单 晶的产业化制造, 并突破 8 in 无微管缺陷 $\mathrm{SiC}$ 单晶 制造瓶颈; 实现 8 in $\mathrm{Si}$ 基 $\mathrm{GaN}$ 电力电子器件产业 化, 突破 12 in $\mathrm{Si}$ 基 $\mathrm{GaN}$ 材料关键技术, $\mathrm{Si}$ 基 $\mathrm{GaN}$ 电力电子器件满足消费类电子、数据中心服务器 电源、工业电源和电动汽车对高效电源管理的更 高需求。

实现 6 in 半绝缘 $\mathrm{GaAs}$ 单晶祄底和 6 in 半绝 缘 $\mathrm{SiC}$ 单晶祄底的自主供货, 确保射频/微波器件 用 $\mathrm{GaAs}$ 和 $\mathrm{GaN}$ 材料相关产业链的供应安全; 突破 6 in GaAs 高电子迁移率晶体管 (HEMT) 外延材料 的量产制造, 达到 “开盒即用” 的技术水平; 突破 6 in 半绝缘 $\mathrm{SiC}$ 祄底上 GaN HEMT 外延材料的生长 和器件技术, 为未来雷达、移动通信技术的发展提 供技术支持。

进一步提高 6 in InP 祄底抛光片的质量, 扩大 产能, 并掌握毫米波器件所需外延材料的量产技术, 达到 “开盒即用” 的技术水平，为第五代移动通信
（5G）技术相关毫米波系统（如汽车防撞雷达、车 间互连与通信系统）的产业链供应安全提供材料支 持。实现 2 in 金刚石自支撑材料和 2 in $\mathrm{Ga}_{2} \mathrm{O}_{3}$ 单晶 祄底的量产, 解决金刚石的 $\mathrm{n}$ 型掺杂和 $\mathrm{Ga}_{2} \mathrm{O}_{3}$ 的 $\mathrm{p}$ 型掺杂问题。

(3) 发光器件用半导体材料

应重视基于 $\mathrm{GaN}$ 的照明用发光器件以及基于 GaAs、InP 的光纤通信用半导体激光器, 适当兼顾 激光投影显示对 $\mathrm{GaN}$ 可见光激光器以及消毒杀菌 用 $\mathrm{GaN}$ 紫外发光二极管, 尤其是深紫外发光器件 的发展; 积极推动应用于显示领域的 Mini LED 和 Micro LED 技术产业化。

(4) 光电探测材料

重点发展对特种光波长产生响应的光电探测器 件、具有超快响应特性的光电探测器件以及超高灵 敏的光电探测器件 (单光子探测为超高灵敏光电探 测的极限要求)。实现 $\mathrm{GaN}$ 紫外探测材料的完全自 主保障, 实现大尺寸 $\mathrm{CdZnTe}$ 单晶材料、 $\mathrm{HgCdTe}$ 外 延材料、GaAs / AlGaAs 量子阱材料、GaAs / InSb II 类 超晶格材料的产业化，实现短波、中波红外探测 器件及焦平面成像芯片的技术突破, 突破长波红 外探测材料、器件和成像芯片的发展, 满足 100 万 像素长波红外焦平面成像芯片以及 $16 \mu \mathrm{m}$ 甚长波 红外探测器件的研制需要。保障超快响应光电探测 器件及材料的供应链安全, 满足我国高速光网的建 设需要。

\section{（5）半导体产业制造 / 封装工艺和材料}

国产光刻胶、超高纯化学试剂及电子气体主要 品种的市场应用占有率达到 30\% 左右, 实现特种 品种的产业化认证, 实现进口产品的部分替代, 形 成全品种、全系列产业能力。其中, $\mathrm{KrF}$ 光刻胶实 现批量生产, $\mathrm{ArF}$ 光刻胶完成认证并进行小批量生 产, 突破高端光刻胶所需的树脂主体材料、光敏 剂、抗反射涂层 (ARC) 等的关键技术。 $0.25 \mu \mathrm{m}$ 到 $0.18 \mu \mathrm{m}$ 掩膜版实现完全自主可控, 高档高纯石 英掩膜基板突破关键技术。

在抛光材料方面, 进一步推进主要品种材料进 入生产线。其中, $\mathrm{Cu}$ 及其阻挡层抛光液、 TSV 抛 光液和 $\mathrm{Si}$ 的粗抛液等全面进入 8 in 和 12 in 芯片生 产线，市场份额从目前的 5\% 提升至 $50 \%$; 针对 硅片的精抛和化合物半导体抛光， $14 \mathrm{~nm}$ 及以下鯺 式场效应晶体管（FinFET）工艺抛光, $\mathrm{Co} 、 \mathrm{Rb}$ 等 
金属互联材料和浅槽隔离（STI）工艺抛光等所 需的抛光液, 实现关键技术突破并小批量生产; CMP 垫 (聚亚氨脂) 产品在 8 in 和 12 in CMP 工艺 中通过应用评估, 实现产品供货。另一方面, 针对 金刚石、 $\mathrm{Ga}_{2} \mathrm{O}_{3} 、 \mathrm{AlN}$ 为代表的新兴半导体材料加 工需要, 开发特种品种的抛光材料, 并获得试用认 证, 形成初步产业能力。

需大力发展大板级扇出 (Fan Out)、TSV/玻 璃通孔（TGV）等新型封装工艺。开发出适用于 $\mathrm{SiC} 、 \mathrm{GaN} 、 \mathrm{Ga}_{2} \mathrm{O}_{3}$ 、金刚石等材料, 满足高温、高压、 高频和大功率需求的封装材料和工艺。

全面发展新型、更高熔点温度的软钎料技术; 开发高效、低成本瞬时液相扩散连接技术、低温烧 结低温连接工艺技术, 解决好银电化学迁移问题; 突破具有良好导热和高温可靠性的封装基板材料 技术，包括 $\mathrm{AlN}$ 和 $\mathrm{Si}_{3} \mathrm{~N}_{4}$ 及其他具备良好导热和 高温可靠性的封装基板材料, 突破活性金属钎焊 在陶瓷材料上覆盖金属的陶瓷覆铜板 (DBC) 技 术, 解决陶瓷与金属的连接问题。突破新型制冷 底板及与热沉连接技术, 大幅度降低功率模块热 阻, 提升性能。

\section{2035 年发展目标}

我国半导体材料及辅助材料 2035 年的发展目 标是: 半导体材料整体技术水平达到国际先进, 产 业水平完全满足产业链供应安全的需要。

(1) 集成电路用半导体材料

具备 18 in 单晶 $\mathrm{Si}$ 材料量产能力, 完成 $5 \mathrm{~nm} /$ $3 \mathrm{~nm}$ 节点集成电路材料的量产技术储备, 突破关键 装备技术, 掌握材料批量生产技术, 打通器件制造 的全流程关键节点技术。

\section{（2）功率和高频器件用半导体材料}

实现 $\mathrm{SiC} 、 \mathrm{GaN} 、 \mathrm{AlN} 、 \mathrm{Ga}_{2} \mathrm{O}_{3}$ 、金刚石等单晶 材料的产业化制造。具体包括: 6 in $\mathrm{GaN}$ 单晶祄底、 8 in $\mathrm{SiC}$ 单晶衬底、6 in AlN 单晶衬底、4 in 金刚石 单晶祄底、6 in / 8 in $\mathrm{Ga}_{2} \mathrm{O}_{3}$ 单晶祄底, 确保整个功 率和高频半导体产业多层次发展的技术需求; 实现 8 in 高质量 $\mathrm{SiC}$ 祄底上 GaN HEMT 外延材料的量产。 解决金刚石的 $\mathrm{n}$ 型掺杂和 $\mathrm{Ga}_{2} \mathrm{O}_{3}$ 的 $\mathrm{p}$ 型掺杂及其制 备工艺难题, 为下一代更高性能功率和高频半导体 器件的产业化及大范围推广应用做好技术储备。

(3) 发光器件用半导体材料

实现 $\mathrm{AlN}$ 单晶祄底上高 $\mathrm{Al}$ 组分 $\mathrm{AlGaN}$ 外延材
料的产业化制造, 突破深紫外发光国产器件制造技 术, 并实现产业化。

\section{(4) 光电探测材料}

满足 1000 万像素长波红外焦平面成像芯片 的研制需要, 突破 18 20 $\mu \mathrm{m}$ 甚长波红外探测器 件技术。

（5）半导体产业制造/封装工艺和材料

对于常规品种的光刻胶、超高纯化学试剂及 电子气体，国产材料的市场占有率达到 $50 \%$ 以上; 对于特种品种的光刻胶、超高纯化学试剂及电子气 体，国产材料的市场占有率达到 30\% 左右，形成 全品种、全系列产品的供应产业链。在抛光材料方 面, 国产常规品种产品的市场占有率超过 $50 \%$; 为 满足金刚石、 $\mathrm{Ga}_{2} \mathrm{O}_{3} 、 \mathrm{AlN}$ 等新兴半导体材料加工 需要所开发的特种抛光材料, 国产化产品的市场占 有率达到 30\%。

\section{四、推动先进半导体材料及辅助材料重大工 程建设}

\section{（一）集成电路关键材料及装备自主可控工程}

\section{1. 需求与必要性}

集成电路关键材料及装备是影响集成电路产业 发展的决定性因素。我国集成电路关键材料自主 可控能力差, 对先进集成电路发展需求极为迫切。 在国家集成电路产业投资基金和现实需求的推动 下, 以市场为导向, “政产学研用金服” 结合, 着 力实施集成电路关键材料及装备自主可控工程迫在 眉睫。为此, 需着重加强两方面建设: 一是人才 队伍建设，包括设置集成电路人才专项基金，加大 核心技术人才的吸引力度; 加强具有示范性微电 子学院的高校支持, 进行集成电路人才的可持续培 养。二是稳定的资金供给。硅片制造属于重资产产 业, 产品验证周期长, 周期性特点明显, 约每 5 年 一个周期, 因此要对发展重点进行谨慎判断。

\section{2. 工程目标}

通过本工程的实施, 加强集成电路关键材料的 产业化能力和可持续研发能力, 扩大集成电路材料 人才培养规模、丰富人才层次体系, 主要的集成电 路材料技术水平达到国际先进，产业水平基本满足 产业链供应安全的需要, 建立起全产业链供货能力, 解除关键行业的 “卡脖子” 隐忧。 
(1) 提升 12 in $\mathrm{Si}$ 单晶及其外延材料的技术水 平, 以满足并进入主流代工厂 $14 \mathrm{~nm}$ 及以下工艺节 点为目标, 在确保集成电路产业链安全的前提下, 逐步扩大国产材料的市场份额。

(2) 开展 18 in Si 单晶及其外延材料研究, 重 点突破 18 in 单晶 $\mathrm{Si}$ 及其外延材料的制造技术, 确 保我国集成电路产业的可持续发展。

（3）通过 TSV、TGV 等新型 $3 \mathrm{D}$ 集成技术研究, 完成后硅时代集成电路的技术路线笁选，在掌握 其材料制备技术的同时，打通后硅时代集成电路 的全产业链技术, 确保 2035 年后, 我国在后硅时 代集成电路领域的产业技术水平和关键行业的供 应链安全。

（4）实现 12 in 及以下大尺寸 $\mathrm{Si}$ 单晶生长设备 及大尺寸晶圆的加工设备自主可控; 开发 18 in 单 晶 $\mathrm{Si}$ 生长设备, 为 $18 \mathrm{in}$ 单晶 $\mathrm{Si}$ 研制和产业化提供 装备支持。

\section{3. 工程任务}

(1) 在大硅片方面, 结合大数据和云计算等技 术发展需求背景, 在国家集成电路专项科技计划资 助的基础上, 一方面, 提升常规 12 in 高品质（满 足 $14 \mathrm{~nm}$ 工艺) 硅片的制造能力, 在 2025 年确保 国内实现量产供应，同时打开国际市场，满足现阶 段经济和社会发展需求; 另一方面, 进一步加强新 技术的研发, 建设 12 in SOI（绝缘祄底上的 $\mathrm{Si}$ )、 射频微波用大尺寸高阻硅 (HR-Si) 祄底的生产能力; 同时对 18 in $\mathrm{Si}$ 祄底进行技术储备, 实现集成电路 技术的可持续发展。

(2) 在集成电路辅助材料方面, 针对品种多、 用量小、生产工艺稳定性差等问题, 建立若干集成 电路辅助材料工程中心，兼顾市场规律和产业供应 链安全两方面因素, 不断强化自主保障意识, 优 先实现量大面广的关键品种的全产业链自主保障, 如 $\mathrm{G}$ 线、 $\mathrm{I}$ 线、 $\mathrm{ArF}$ 光刻胶及配套试剂、 $\mathrm{Cu}$ 及其 阻挡层抛光液、 TSV 抛光液、 $\mathrm{Si}$ 粗抛液、 $60 \mathrm{~nm}$ 及 $90 \mathrm{~nm}$ 以上制程产品的掩膜版等, 确保产业供应链 的相对安全。对标集成电路先进制程, 开发 $\mathrm{ArF}$ 、 EUV 和电子束光刻胶, 高档高纯石英掩膜基板、掩 膜保护膜, 以及 $\mathrm{Si}$ 片精抛和化合物半导体抛光液, $14 \mathrm{~nm}$ 以下 FinFET 工艺和 $\mathrm{Co} 、 \mathrm{Rb}$ 等金属互联材料、 STI 等抛光液, 为半导体产业的发展提供技术及产 业支持。
（3）在半导体关键设备方面, 对国产品牌还需 进行产业链及政策的重点培育。在国家科技重大专 项 “极大规模集成电路制造技术及成套工艺” 项目 （02 专项）成果的基础上，加强对装备与材料、工 艺一体化的研制, 通过国产化装备验证平台, 开展 对装备可靠性和工艺稳定性的验证与考核, 加速开 展高端装备研制。总之, 在解决有无问题的基础上, 解决做大做强的问题。

（4）在人才培养方面, 半导体专业人才特别是 高端人才短缺, 一直是制约我国半导体产业可持续 发展的关键因素。设置半导体人才专项基金，加大 核心人才引进力度; 加快建设微电子产教融合协同 育人平台, 保障我国半导体产业的可持续发展。

(二) $\mathrm{SiC}$ 和 $\mathrm{GaN}$ 半导体材料、辅助材料、工艺及装 备验证平台

1. 需求与必要性

经过近 10 年的发展, 我国基本建立了以 $\mathrm{SiC}$ 和 $\mathrm{GaN}$ 为代表的第三代半导体材料、工艺和装备 产业体系。该类材料紧密围绕光电子、新能源、 $5 \mathrm{G}$ 等热点应用, 在未来 5 年内将迎来产业化发展 的重要机遇。然而, 同第一代半导体产业类似, 我 国第三代半导体产业的发展依然面临诸多问题，如 产业链各环节所用的关键装备、仪器、耗材等多为 进口，尚未实现技术、装备的自主可控，增加了产 业供应链的不安全性; 国产化装备、仪器、耗材难 以与产业应用对接, 不利于产业生态和各环节的健 康发展; 进口材料和装备一次性投入和后续维护价 格昂贵等。为此, 需要建立化合物半导体材料、辅 助材料、工艺和装备国产化验证平台。

\section{2. 工程目标}

建立 $\mathrm{SiC}$ 和 $\mathrm{GaN}$ 半导体材料生长、加工、 芯片工艺和封装检测公共验证平台, 实现 6 in/ 8 in $\mathrm{SiC}$ 单晶祄底和外延材料生长的批量生产, 国 产化率达到 70\%; 6 in $\mathrm{SiC}$ 上 $\mathrm{GaN}$ 外延材料与高 功率射频器件和 8 in $\mathrm{Si}$ 上 $\mathrm{GaN}$ 外延材料与功率 器件实现量产，国产化率达到 70\%; 部分 6 in/ 8 in 材料生长及加工装备、配套原材料和零部件实 现国产化批量替代，装备国产化率达到 70\%。

\section{3. 工程任务}

化合物半导体材料、辅助材料、工艺和装备国 产化验证平台的工程任务主要包括：晶体材料生长 
设备及其辅助原材料、零部件验证, 晶体材料切、 磨、抛加工材料与设备验证, 芯片工艺装备、工艺 流程、原辅料与关键零部件验证, 封装与检测装备、 流程、原辅料与关键零部件验证。

（1）晶体材料生长设备及其辅助原材料、零部 件验证

多数化合物半导体材料仍处于技术开发与突破、 产业化验证的阶段, 相关企业和研发机构对于单晶 生长技术与设备、各类原材料、零部件等的验证有 很大需求。特别是随着技术的发展, 新材料、新技 术、新结构不断涌现, 该验证平台将会促进协同研 究, 加速技术升级和完善, 降低研发和验证成本。 通过建立针对不同材料采用不同原理 (如 $\mathrm{SiC}$ 单 晶籽晶升华法、液相外延法, $\mathrm{GaN}$ 的氢化物气相外 延法、金属有机物化学气相外延法、氨热法等）的 单晶生长炉, 开展对长晶新技术、新装备、辅助原 材料和关键零部件的研究与验证。

（2）晶体的切、磨、抛加工材料与设备验证

化合物半导体普遍具有硬度高、化学性能稳定 的特点, 加工难度大, 而后续的外延和芯片工艺又 对晶体加工提出了更高要求。因此, 建立晶体的切、 磨、抛加工材料与设备验证平台, 具备不同材料和 不同原理加工能力, 并能对加工材料、加工方法和 装备进行验证。

（3）芯片工艺装备、工艺流程、原辅料与关键 零部件验证

新建 6 in / 8 in $\mathrm{SiC} 、 6$ in / 8 inGaN工艺平台, 或 者运用政府采购的服务方式将已有工艺平台变为公 共工艺平台, 为研发机构和企业提供相应服务。这 些平台需具备的功能和能力为: 提供小批量芯片工 艺代工, 定制化工艺流程开发, 国产化原辅料、零 部件和工艺装备等新技术、新产品测试和验证, 并 根据需要进行长期运行考核。

（4）封装与检测装备、流程、原辅料与关键零 部件验证

面向电力电子、微波射频等不同应用需求, 建 立具备高压、大功率、高频、高温封装等特性的能 力, 构建器件与模块烧结、焊接、压接、3D 封装 等多种封装技术平台。研发具备国际领先水平的烧 结、焊接、压接、3D 封装设备、辅助设备和测试 设备, 并能够开展模具设计、材料 (如绝缘材料、 互联材料、底板材料等）选择、技术开发、设备保
障、测试分析以及可靠性验证。进行平台系统软件 的开发以及数据库建设, 联合上下游企业开展共性 技术研发, 共享专利和服务成果, 形成开放、共享 的运行机制。平台需提供小批量的封装和测试代工, 定制化的封装技术开发, 国产化原辅料、零部件和 封装装备等新技术、新产品的测试和验证，并根据 需要安排长期运行考核。

\section{（三）先进半导体材料在 5G、能源互联网及新能源 汽车领域的应用示范工程}

1. 需求与必要性

化合物半导体材料和器件在 $5 \mathrm{G}$ 、能源互联网、 新能源汽车、光伏逆变器等领域的应用, 符合智能 化发展、节能减排、产业自主可控等国家重大战略 需求, 能够为相关产业抢占未来发展的战略性和引 领性技术制高点提供关键技术和产业支撑 $[10,11]$ 。 未来 5 年, $\mathrm{GaN}$ 射频器件将在 $5 \mathrm{G}$ 基站、微基站和 移动终端中迎来巨大市场, $\mathrm{GaN}$ 功率器件将在消费 类电子、数据中心服务器电源和光伏逆变器领域得 到广泛应用; $\mathrm{SiC}$ 功率器件将在能源互联网中的电 力路由器、新能源汽车中得到广泛应用。未来 5 年, 上述 3 个发展方向的国内市场规模将超过千亿元。

现阶段，化合物半导体相关技术已经具备产业 化基础, 在 $5 \mathrm{G}$ 、新能源并网、新能源汽车等领域 的应用市场已经启动。国际上, 为提高未来的竞争 力, 美国科锐公司、德国英飞凌科技公司、日本罗 姆半导体集团等产业龙头企业已经开始了产业与市 场布局。相对而言，国内的机构和企业布局分散、 技术和产业化能力较弱, 面对即将到来的产业竞争, 国内企业还需要政府通过应用示范工程, 达到技术 和产业协同发展、产业化技术快速成熟、产业能力 快速壮大的目的。

\section{2. 工程目标}

以应用示范工程为牵引, 带动 $\mathrm{GaN}$ 和 $\mathrm{SiC}$ 材 料、芯片工艺和器件封装与系统集成技术加速发展, 实现产业化。GaN 射频器件在 $5 \mathrm{G}$ 基站和微基站的 国产化率达到 50\%, 在移动终端领域的国产化率 达到 70\%; GaN 功率器件在消费类电子领域的国产 化率达到 $80 \%$, $\mathrm{SiC}$ 功率器件在电力路由器、新能 源汽车应用领域的国产化率达到 $50 \%$ 。

\section{3. 工程任务}

开展 $\mathrm{SiC}$ 基 $\mathrm{GaN}$ 外延材料与 $\mathrm{GaN}$ 射频器件、 
$\mathrm{Si}$ 基 $\mathrm{GaN}$ 外延材料与 $\mathrm{GaN}$ 功率器件、 $\mathrm{SiC}$ 功率器件 及其模块封装与系统集成等方面的技术研发和产 业化。

(1) 在 $\mathrm{GaN}$ 外延材料方面, 突破 6 in 高质量 $\mathrm{SiC}$ 基 $\mathrm{GaN}$ 外延材料生长技术，进一步降低异质外 延 GaN HEMT 材料中的位错和缺陷密度，显著提 升 $\mathrm{AlGaN} / \mathrm{GaN} 、 \mathrm{AlN} / \mathrm{GaN} 、 \mathrm{InAlGaN} / \mathrm{GaN}$ 异质 结材料质量、电学性能和可靠性。通过材料体系、 生长技术和电路设计技术的创新, $\mathrm{GaN}$ 微波大功率 器件工作电压提高到 $100 \mathrm{~V}$ 以上, 开发 $10 \mathrm{~kW}$ 以上 $\mathrm{GaN}$ 微波功率器件, 在 $175^{\circ} \mathrm{C}$ 结温下的平均失效时 间（MTTF）达到千万小时, $\mathrm{GaN}$ 微波功率器件和 单片电路性能达到国际先进水平。

(2) 在 $\mathrm{GaN}$ 功率器件方面, 首先实现 8 in $\mathrm{Si}$ 基 $\mathrm{GaN}$ 外延材料和功率器件技术产业化。 $\mathrm{GaN}$ 功 率器件的额定电压达到 $650 \mathrm{~V}$, 导通电阻低于 $10 \mathrm{~m} \Omega$, 封装后功率模块的电流达到 $100 \mathrm{~A}$, 满足 各类电源适配器、光伏逆变器、车载充电器等应用 需求。

(3) 开发 $\mathrm{SiC}$ 高压器件所需的大尺寸、高均匀 性、低缺陷密度祄底和超厚 $\mathrm{SiC}$ 外延材料。开发万 伏级 $\mathrm{SiC}$ 二极管、金属 - 氧化物半导体场效应晶体 管（MOSFET）、绝缘栅双极晶体管（IGBT）以及门 极可关断晶闸管 (GTO) 等高压 $\mathrm{SiC}$ 电力电子芯片; 开发千安级 $\mathrm{SiC}$ 高温、高压、大功率封装模块; 建 立高压、大功率 $\mathrm{SiC}$ 功率器件与模块的测试、可靠 性评价体系。

（4）采用高压、大功率全 $\mathrm{SiC}$ 模块, 开发新型 电力路由器, 并具备工程示范应用能力; 开发车规 级的 $1200 \mathrm{~V}$ 和 $1700 \mathrm{~V}$ 全 $\mathrm{SiC}$ 功率模块, 开发车载 充电和电机驱动控制系统, 并通过车规级认证。

\section{五、对策建议}

（一）抓住战略发展机遇期，坚持政策推动、企业 和机构主导，整合国内优势资源，推动产业 有序发展

1. 发挥龙头企业引领作用, 形成 “链式集聚”

目前, 国内具备发展半导体产业的企业和地区 并不多, 为有效利用财政、人才和社会资源, 亟需 做好顶层设计和优化布局，遴选出具备行业技术和
资源优势的企业和机构，进行资金重点支持和政策 扶植。推动龙头企业和机构通过技术、管理和商业 模式创新, 推进产业 “链式集聚”。发挥龙头骨干 企业在自主创新和产业发展中的创新引领与示范带 动作用, 形成研发和品牌优势, 最终巩固和形成多 个区域布局合理、产业优势明显的国家半导体技术、 人才和产业高地。

2. 器件切入, 以点带面, 有序推进

具有技术和工艺领先、满足市场需求的核心器 件, 一直是半导体产业发展的 “硬道理”。政府相 关部门应围绕未来技术和产业发展的重要方向, 如 $5 \mathrm{G}$ 、人工智能 $(\mathrm{AI})$ 、工业互联网、新能源等, 开 展相关芯片设计、芯片工艺、先进封装等技术攻关 和产业化突破。建设国家级的面向高校、科研院所 和初创企业的软件与硬件、单晶生长与外延、芯片 工艺、封装等中试平台, 建设具备先进工艺和运营 水平的代工厂, 推动建设具有自主可控能力的垂直 整合制造企业。

3. 建立分段平台, 加快整线集成

建立分段工艺设备技术研发平台和工艺验证平 台。遵循工艺指导材料、设备研发原则，借鉴国外 先进技术，同时进行 “产学研” 结合的协同创新, 开发满足产业要求的半导体关键设备。通过分段工 艺设备技术研发平台和工艺验证平台, 实现关键设 备牵引, 分段工艺局部成套, 拓展解决整线成套设 备国产化，实现整线集成，掌握一系列相关核心技 术，培养一支骨干技术人才队伍和一支高水平科研 与产业化管理队伍, 全面提升研发与制造能力, 推 动我国半导体产业的自主可控发展。

\section{4. 推动示范应用, 提升国产化水平}

推动国产装备、材料与器件的示范应用。国产 材料、器件、装备试验验证所需的费用大、时间周 期长，批量化生产存在客户验证、技术迭代、市场 准入等门槛，如果没有相关政策推动，用户使用国 产材料、装备和器件的意愿度较低。因此, 政府 相关部门应以扶植国产化为出发点, 通过政策法 规、资金奖励等一系列配套政策，配合和组织政 府采购方式的示范应用，鼓励终端企业积极采用 国产材料、器件和装备, 使上游企业积累工艺参 数和应用数据, 加速提升国产材料、器件和装备 性能, 最终实现国产化。 
（二）把握 “超越摩尔” 的历史机遇，布局下一代 集成电路技术

半导体技术从诞生开始, 一直遵循着摩尔定律 的路线快速发展, 并通过各种技术创新来延续摩尔 定律。但是, 传统的摩尔定律发展到今天, 既有路 径已经开始显现出尽头。因此, 需突破 “摩尔定律” 所划定的边界, 在更广阔的领域探索创新, 开启探 寻 “超越摩尔”之路 [12]。“超越摩尔” 在异质集成、 新型计算范式、超越互补金属氧化物半导体信息处 理器件等技术及应用中, 已展现出巨大潜力。以此 为出发点, 我国在半导体和集成电路技术领域需抓 住这一历史机遇。

推动建设国家 “超越摩尔” 联合实验室, 开展 下一代集成电路基础理论、技术路线、核心技术研 究, 为产业化发展提供强有力的理论支撑。加快新 材料、新工艺、新装备人才的培养, 建立 “产学研” 协同创新机制。结合产业发展需求, 开展应用驱动 的产业化技术研究, 瞄准 5G、AI、大数据、工业 互联网、能源互联网、智能网联新能源汽车等现实 需求, 进行产业化示范。

\section{（三）构建产业技术创新链, 加快创新生态建设}

\section{1. 继续加强创新能力建设}

加大研发投入力度, 重视微电子及半导体材料 基础研究。重点支持一批优势机构和企业, 使其成 为具有一定规模、特色鲜明、掌握核心技术的科研 和行业龙头。鼓励创新性企业在半导体精密加工, 新型半导体材料及工艺制备, 新工艺制程及先进封 装等方面大胆创新, 不断拓展和延伸产业链, 提高 产品附加值, 推动半导体产业向更高层次发展。不 断完善和创新科技管理体制机制, 优化配置创新资 源, 提高创新效率。

2. 加快构建公共研发和科技服务平台, 建设科 技创新产业基地

以应用需求为牵引, 梳理出具有产业化前景、 体系化的关键技术, 支持工程化试验与验证平台建 设。由产业联盟、研究机构、优势企业和投资机构 等联合组成新型研发机构, 建立体制和机制创新的 开放型国际化公共研发与服务平台, 形成核心技术 突破、系统集成、测试验证、可靠性评价等工程试 验验证能力。建立具备成果转移、转化、孵化与服 务职能的专业化众创空间, 加速实现科技成果的产
业化和以产业链为线索的 “链式集聚”。采取政府 购买服务、资助、奖励等方式, 积极扶持创新企业 成长和发展。综合考虑资金、人才、市场和生态环 境等因素, 按照产业差异化、效益最大化、特色显 著的原则落地创新产业基地。

3. 实施 “技术原创、知识产权和标准” 战略

构建以技术原创、知识产权和标准三要素为特 征的高技术成果产业模式, 提高产业竞争优势。立 足自主创新, 构建标准体系, 形成标准检测和认证 能力, 实施技术创新、知识产权和标准战略。

4. 促进分层次、多类型、跨界创新人才队伍的 聚集与合作

将人才队伍建设与研发任务、基地建设相结合, 结合已有的人才计划, 形成一批引领半导体材料领 域发展的领军人才。以重点专项和重大工程为依托, 实行 “人才 + 项目 + 基地”一体化培养, 建立全链 条人才团队培育机制。加强前瞻性技术人才团队培 养, 围绕半导体材料研究前沿方向, 组建技术人才 团队。积极引进产业发展所需的高层次人才和紧缺 人才, 同时加快建设和发展职业培训教育, 大力培 养专业技术人才, 提高产业技术队伍整体素质, 完 善面向半导体材料产业的人才服务体系。

\section{5. 拓展国际合作空间}

采取 “走出去和请进来” 相结合的方式, 创新 国际合作模式。鼓励国内有实力的企业和科研机构 在国外设立半导体研发机构, 并开展与国外半导体 企业、科研院校的研发合作。支持国内企业和机构 并购境外半导体企业, 积极参与国际技术和产业联 盟, 拓展国际合作渠道, 提升国际资源整合能力, 实现国际化经营。在国内有条件的地区, 建立国际 技术合作、技术转移、成果孵化、成果产业化、科 技服务等有特色的国际合作区域, 吸引有实力的跨 国公司和机构以独资或合资方式在国内建立高水平 的研发中心、生产中心和运营中心, 以此带动国内 行业和企业对接国际资源。

\section{参考文献}

[1] 赵婉雨. 聚焦产业关键技术, 把握第三代半导体发展机遇一 第三代半导体材料产业技术分析报告 [J]. 高科技与产业化, 2019 (5): 28-40.

Zhao W Y. Focus on key technologies and seize opportunities-An industrial and technical analysis report of the 3rdgeneration-semiconductor materials [J]. High-Technology \& 
Commercialization, 2019 (5): 28-40.

[2] 朱泓达. 中国半导体硅的现状与发展趋势 [J]. 数字通信世界, 2020 (6): 268, 278.

Zhu H D. Current situation and development trend of semiconductor silicon in China [J]. Digital Communication World, 2020 (6): 268, 278.

[3] 韩秀栋, 王熙大, 王亚会, 等. 天津市半导体材料产业发展方向 及对策研究 [J]. 天津科技, 2019, 46(12): 11-12, 15.

Han X D, Wang X D, Wang Y H, et al. Research on development direction and countermeasures of semiconductor materials industry in Tianjin [J]. Tianjin Science \& Technology, 2019, 46(12): $11-12,15$.

[4] 戴渊. 5G产业发展现状及趋势解析 [J]. 电子测试, 2019 (11): $137-138$

Dai Y. Analysis of the development status and trend of $5 \mathrm{G}$ industry [J]. Electronic Test, 2019 (11): 137-138.

[5] GaN RF market growing at $12 \%$ CAGR to $\$ 2$ bn in 2025, driven by $5 \mathrm{G}$ infrastructure and defense applications [J]. Semiconductor Today, 2020, 15(4): 64-65.

[6] 第三代半导体产业技术创新战略联盟. 2019第三代半导体产 业发展报告 [R/OL]. (2019-12-01) [2020-08-15]. http://www.casa-china.cn/uploads/soft/200529/6_1446304641.pdf.

China Advanced Semiconductor Industry Innovation Alliance. Third generation semiconductor industry development report 2019 [R/OL]. (2019-12-01)[2020-08-15]. http://www.casa-china.cn/ uploads/soft/200529/6_1446304641.pdf.

[7] 宋维东. 碳化硅半导体材料的研究现状及发展前景 [J]. 中国粉 体工业, 2020 (2): 8-11.
Song W D. Research status and development prospect of silicon carbide semiconductor materials [J]. China Powder Industry, 2020 (2): $8-11$

[8] 史冬梅, 杨斌, 蔡韩辉. III族氮化物第三代半导体材料发展现状 与趋势 [J]. 科技中国, 2018 (4): 15-18.

Shi D M, Yang B, Cai H H. Development status and trend of III nitride third generation semiconductor materials [J]. China SciTechnology Business, 2018 (4): 15-18.

[9] 朱雷, 王轶㳥, 戴梅. 我国集成电路材料专题系列报告 [R/OL]. (2019-07-15) [2020-08-15]. http://news.eeworld.com.cn/mp/XSY/ a69514.jspx.

Zhu L, Wang Y Y, Dai M. A series of reports on China's IC materials 2019 [R/OL]. (2019-07-15) [2020-08-15]. http://news.eeworld. com.cn/mp/XSY/a69514.jspx.

[10] 邓小川, 谭轱, 万殊燕, 等. 超高压 $\mathrm{SiC}$ 电力电子器件及其在电网 中的应用 [J]. 智能电网, 2017, 5(8): 733-741.

Deng X C, Tan B, Wan S Y, et al. Ultra high voltage SiC power electronic device and its application in power grid [J]. Smart Grid, 2017, 5(8): 733-741.

[11] 曾正, 郡伟华, 胡博容, 等. $\mathrm{SiC}$ 器件在光伏逆变器中的应用与挑 战 [J]. 中国电机工程学报, 2017, 37(1): 221-232.

Zeng Z, Shao W H, Hu B R, et al. Chances and challenges of photovoltaic inverters with silicon carbide devices [J]. Proceedings of the CSEE, 2017, 37(1): 221-232.

[12] 武俊齐, 赖凡. 后摩尔时代新兴计算芯片进展 [J]. 微电子学, 2020, 50(3): 385-388.

Wu J Q, Lai F. Progress of new computing chips in the more than Moore's era [J]. Microelectronics, 2020, 50(3): 384-388. 